Indexed by

\title{
Scopus
}

\section{PREVENTION OF SCALE IN THE DOWNHOLE EQUIPMENT AND PRODUCTIVE RESERVOIR DURING THE OIL WELL OPERATION}

Crossref

KOBSON

\section{Lilya Saichenko}

Saint Petersburg Mining

University, Oil and Gas Faculty,

Development and Operation

Oil and Gas Fields,

ROAD Saint Petersburg, Russia
Dmitry Tananykhin

Saint Petersburg Mining

University, Oil and Gas Faculty,

Development and Operation

Oil and Gas Fields,

Saint Petersburg, Russia
Rahman Ashena

Bear and Brook Consulting,

Brisbane, Australia

Key words: scale, scale inhibitor, co-produced water, bottom-hole formation zone, supersaturation

Cite article:

Lilya, S., Dmitry, T., \& Rahman A. [2021]. Prevention of scale in the downhole equipment and productive reservoir during the oil well operation. Journal of Applied Engineering Science, 19(2), 363 - 368. DOI:10.5937/jaes0-29696

Online aceess of full paper is available at: www.engineeringscience.rs/browse-issues 
doi:10.5937/jaes0-29696

\title{
PREVENTION OF SCALE IN THE DOWNHOLE EQUIPMENT AND PRODUCTIVE RESERVOIR DURING THE OIL WELL OPERATION
}

\author{
Lilya Saichenko ${ }^{1 *}$, Dmitry Tananykhin ${ }^{1}$, Rahman Ashena2 \\ ${ }^{1}$ Saint Petersburg Mining University, Oil and Gas Faculty, Development and Operation Oil and Gas Fields, \\ Saint Petersburg, Russia \\ ${ }^{2}$ Bear and Brook Consulting, Brisbane, Australia
}

The problem of scale is very common in the process of oil production at the initial and the final stages of field development. Inorganic scale may precipitate from the formation fluids in various elements of the oilfield system in the oil extraction process. These scales, which collect under certain thermodynamic and physical-technical conditions, cause a decrease in equipment reliability and productivity. The article highlights the main factors affecting the process of scale in field conditions, and evaluates the effectiveness of scale inhibitors. It is noted that at wells with periodic inhibition, it is necessary to switch to more modern protection technologies - constant dosing of the inhibitor into the annulus and setting the inhibitor in the bottom hole formation zone.

Key words: scale, scale inhibitor, co-produced water, bottom-hole formation zone, supersaturation

\section{INTRODUCTION}

The scale has a complex composition; they contain not only mineral salts, but organic components as well. In each particular case, the determining mineral components are one or two such compounds: for example, scale in the downhole equipment of wells in the West Siberian fields contains calcium carbonate and in some cases also magnesium carbonate. The rate and conditions of precipitation of solid scale depend not only on the conditions that determine inorganic compounds but also on organic compounds, the molecular surface properties and, the chemical activity of the latter. Precipitation from oil wells includes calcium carbonates and sulfates, barium sulfate, and calcium chloride. Each of these types of salts can act as the main component of scale on a particular object, occupying from about 40 to $90 \%$ of the total volume of it. The remaining $10-60 \%$ is usually sodium chlorides, barium and magnesium carbonates, corrosion products, oil components, gas inclusions, and mechanical impurities [1-10].

Scale formation is the process of precipitation and accumulation of poorly soluble inorganic compounds caused by supersaturation of that compound in the solution. Supersaturation occurs when the concentration of a compound in a solution exceeds the equilibrium.

The main factors that affect the process of scale precipitation in the field conditions include [11-14]:

- mixing of flood water with and the one in the reservoir (in the productive reservoir), which leads to the concentration of a compound above the equilibrium;

- contact of water moving in the reservoir (both reservoir one and flood water one) with the reservoir formation;
- diffusion from oil to water of active water-soluble components, which are adsorbed on the surface of incipient salt crystal, which in turn stimulates the growth of crystals in certain environments and their adhesion to the surfaces of downhole equipment, production tubing and formation;

- changes in thermodynamic conditions (pressure, temperature).

The effects of these factors manifest complexly and simultaneously. Some factors are ambiguous. For example, the increase of the temperature increases the solubility of gypsum, which reduces scale formation, yet the evaporation of the solvent with increasing temperature increases the concentration of gypsum, which generally stimulates scale.

There may be other reasons for the scale formation. For example, laminar-turbulent transition in flow wells and especially in gas-lift wells contributes to the buildup of scale on the walls of production tubing, which is explained by the destruction of the wall hydrodynamic layer of the liquid. After its breakdown, microparticles of scale adhering to the wall serve as sedimentation centers.

To identify the most significant causes of scale formation and accumulation at the oil-field equipment, it is necessary to conduct special physical and chemical studies at each specific field.

The main purpose of the work is to analyze the current state of technologies and technical means used in the operation of wells to prevent the scale in downhole equipment, as well as to study the composition and properties of scale, the effectiveness of used inhibitors. 


\section{MATERIALS AND METHODS}

Mixing of incompatible waters, leading to scale, occurs when the well is put on stream after well killing operation, with various methods of water flooding, when incompatible water from various oil layers is mixed at the bottom of the well, etc. For example, in the case of peripheral waterflooding, mixing of injected and edge water can lead to sedimentation in the aquifer part of the reservoir, while in the case of contour waterflooding, water injected directly into the oil part of the reservoir is mixed with irreducible water (capillary and residual) in the pores of the oil reservoir. In the case of water incompatibility in the reservoir the formation of insoluble scale is possible, complicating the oil filtration process.

When the well is put on stream after well killing operation, the produced water is mixed with the well-killing fluid. When mixing, for example, of the well-killing fluid based on calcium chloride with produced water of the sodium-bicarbonate type, a formation of supersaturated calcium carbonate solution is possible, due to an increase in the content of calcium ions and a decrease of carbon dioxide in the produced water, leading to the precipitation of calcium carbonate in the wellbore and the downhole equipment [14-17].

Scale of calcium carbonate also occurs when wells are killed with solutions prepared on sodium chloride base and other salts, as well as with emulsion mixtures. In this case, the precipitation of calcium carbonate is due only to a decrease in the content of dissolved $\mathrm{CO} 2$ when mixing saturated or near-saturated produced water with the well-killing fluid $[18,19]$.

Due to the different permeability of the oil reservoir layers in the wellbore, associated produced waters with different content of salt-forming ions and dissolved $\mathrm{CO} 2$ are mixed, which often leads to the formation of water solutions supersaturated with calcium carbonate and carbonate precipitation in the wellbore. This factor can decisively influence scale when the flood water enters the bottom-hole formation zone of the well. The mixtures of water most susceptible to calcium carbonate precipitation are of the calcium chloride type with sodium bicarbonate. The amount of calcium carbonate formed when calcium chloride water is mixed with sodium bicarbonate water depends on the volume ratio in which these waters are mixed [20-22].

The analysis of the Priobskoye field's production well stock failures in recent years showed an increase in the equipment failures that revealed scale during disassembly. The sample included 453 failures, the average time between overhauls was 200 days. In $48 \%$ of cases the presence of scale was noted, in $39.6 \%$ cases there were hard particle impurities, and only in $5.3 \%$ cases, corrosion was found. More than $40 \%(41.2 \%)$ failures were caused by scale and mechanical impurities.

As can be seen, the presence of scale is found in almost half of the cases of equipment failures. This does not mean that the failure of electrical submersible pump unit (ESP) occurred directly due to scale, but, still, the presence of inorganic salts is undesirable [23-25].

To analyze the composition of scale, sediments were collected from the impellers of the ESP of different manufacturers and different wells. All the pumps operated at the Priobskoye field.

The analysis of the sample composition was performed by the microprobe method; the elemental composition was determined with the JXA-6400 electron probe analyzer. The total content of petroleum products and water was determined by the sediment weight change washing with an alcohol-benzene mixture. The content of mechanical impurities soluble in $\mathrm{HCl}$ was measured by the precipitate weight change after washing with hot $10 \% \mathrm{HCl}$. The concentration of iron ions (to calculate the content of iron compounds) was determined in the filtrate after washing the sediment using the photocolorimetric method. The analysis of the sample composition was carried out according to the Russian National Standard 6370-83 "Method for determining the content of mechanical impurities". The appearance of the samples and their characteristics are shown below.

Evaluation of the effectiveness of scale inhibitors for sedimentation preventing was carried out according to the NACE TM 0374-2007 in a liquid solution of the average model of produced water of the Priobskoye field $\left(\mathrm{Ca}^{2+}=\right.$ $221,44, \mathrm{Mg}^{2+}=78,43, \mathrm{HCO}_{3^{-}}=1122,4, \mathrm{CO}_{3}{ }^{2}-=6,0, \mathrm{Na}^{+}$, $\left.\mathrm{K}^{+}=6778,72, \mathrm{Cl}^{-}=10401,5, \mathrm{Fe} .=0,8, \mathrm{SO}_{4}{ }^{2}-=3,85\right)$.

\section{ANALYSIS OF SCALE}

The precipitation on the surface of the ESP impellers was composed mostly of calcite and corrosion products, and in two cases also quartz sand and proppant were detected.

Scale taken from the equipment of well No. 14096 (Figure 1) consisted of a calcite crust about $1 \mathrm{~mm}$ thick, in the form of aggregates of rhombohedral crystals of a light gray color. On the inner side of the crust, there was a thick coating of iron hydroxides (corrosion products). The sediments contained rare rounded quartz grains and their fragments; grain sizes were $0.1-0.3 \mathrm{~mm}$, rarely up

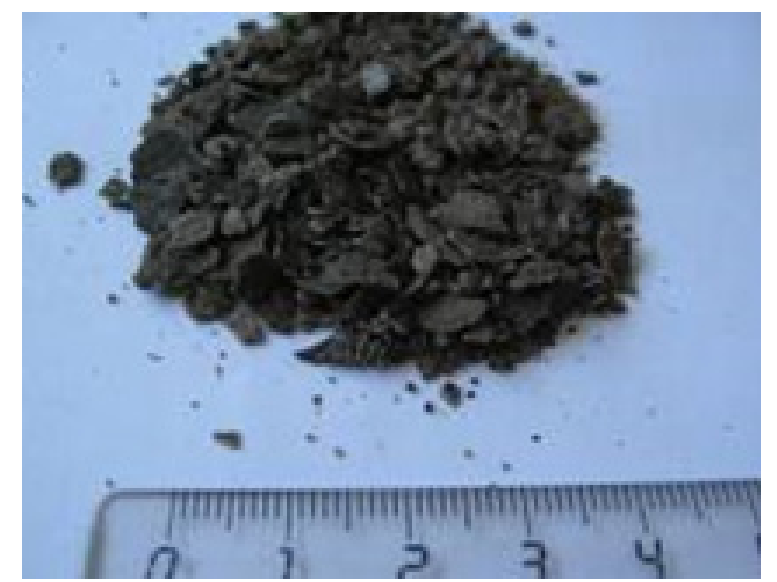

Figure 1: Appearance of scale from well No. 14096 
to $0.6 \mathrm{~mm}$, some proppant balls are present. The composition of scale from well No. 14096 is shown in the Table 1.

Table 1: Composition of scale from well No. 14096

\begin{tabular}{|c|l|c|}
\hline № & Component of scale & Content, $\%$ \\
\hline 1 & petroleum products & 4,5 \\
\hline 2 & ferrous oxide & 4,1 \\
\hline 3 & calcite & 91,4 \\
\hline
\end{tabular}

Scale taken from the equipment of well No. 12436 (Figure 2) were represented by a calcite crust less than 1 $\mathrm{mm}$ thick, composed of an aggregate of parallel-columnar gray crystals. On the inner surface of the crust, there was an uneven coating of iron hydroxides (corrosion products). The composition of scale from well No. 12436 is shown in the Table 2.

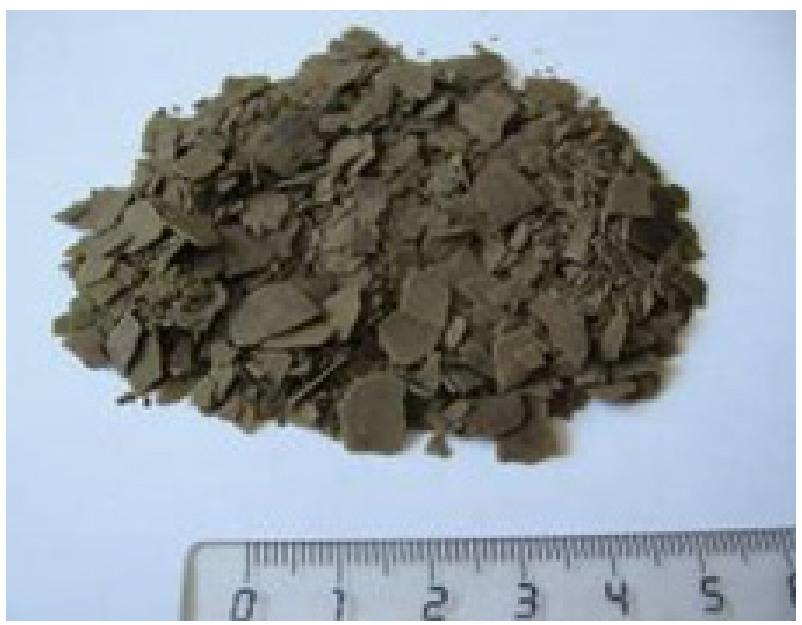

Figure 2: Appearance of scale from well No. 12436

Table 2: Composition of scale from well No. 13096

\begin{tabular}{|c|l|c|}
\hline № & Component of scale & Content, \% \\
\hline 1 & petroleum products & 4,2 \\
\hline 2 & ferrous oxide & 12,6 \\
\hline 3 & calcite & 83,2 \\
\hline
\end{tabular}

Scale taken from the equipment of well No. 19617 (Figure 3) were represented by crust-like formations less than $1 \mathrm{~mm}$ thick, composed of a gray cryptocrystalline aggregate. The surface of the crust was unevenly covered with brown iron hydroxides. The deposit was 90$95 \%$ consisted of oil-saturated calcite and 5-10\%corrosion products represented by powdery brown particles. The composition of scale from well No. 19617 is shown in the Table 3.

Table 3: Composition of scale from well No. 19617

\begin{tabular}{|c|l|c|}
\hline № & Component of scale & Content, \% \\
\hline 1 & petroleum products & 5,2 \\
\hline 2 & ferrous oxide & 3,6 \\
\hline 3 & calcite & 91,2 \\
\hline
\end{tabular}

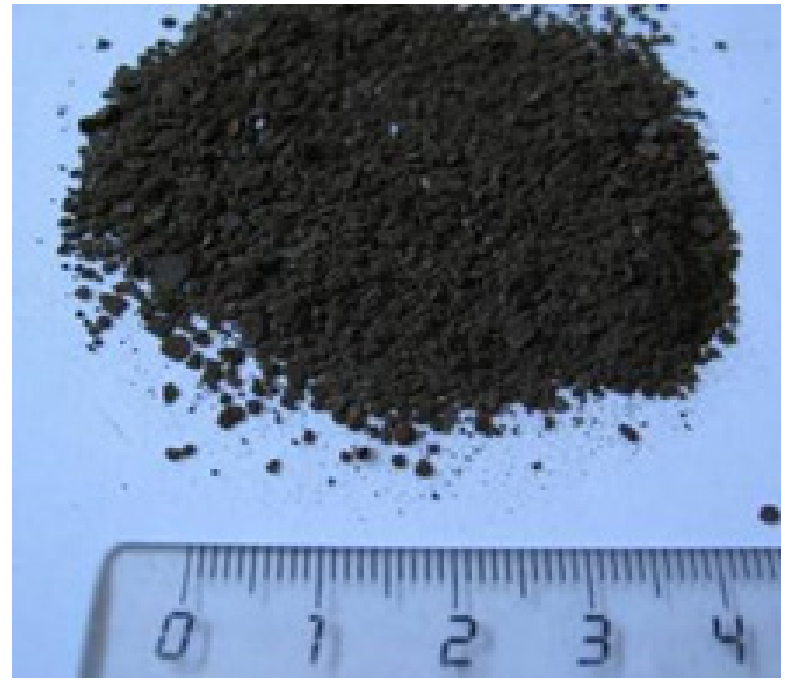

Figure 3: Appearance of scale from well No. 19617

\section{EFFECTIVENESS OF USED SCALE INHIBITORS}

Under the current conditions, the most appropriate way to prevent scale at the Priobskoye field was to inhibit the products using scale inhibitors, effectively preventing the deposition of calcium carbonate, the main scale at this field. The method of using inhibitors occupies a special place due to its productivity and efficiency in the field conditions. To design this method, i.e. select the type of inhibitor, its optimal concentration in the treated medium, the method of introduction etc. it is necessary to understand the action mechanism of scale inhibitors slowing down the sedimentation.

Inhibitor molecules diffuse through the solution and are adsorbed on the surface of salt microparticles. Stable associations form, and the further growth of these stops. The inhibitor adsorption layer on the crystal surface not only suppresses their growth but also prevents the crystals from connecting and sticking to the surface of equipment and tubing. The associations due to their small size are easily transferred by the solution.

The effect of the inhibitor is related to its concentration in the solution (Figure 4).

The minimum threshold concentration (zone 1) corresponds to the molar ratio of the inhibitor and the precipitating cation from 1:104 to 1:2.5. This very ratio corresponds to the minimum consumption of the reagent with the maximum inhibitory effect and should be maintained for industrial use of the reagent.

Zone 2 is associated with the appearance of secondary precipitation, which is a sparingly soluble inhibitor and cation compounds.

At the maximum concentration (zone 3), water-soluble complexes are again formed, with the ratio of the inhibitor to the precipitation-forming cation is $10: 1$ or more. Such concentrations are unattainable in field practice.

It is necessary to switch gradually to more modern protection technologies at wells with periodic inhibition: 
constant dosing of the inhibitor into the annular space and setting the inhibitor in the bottom-hole zone of the formation.

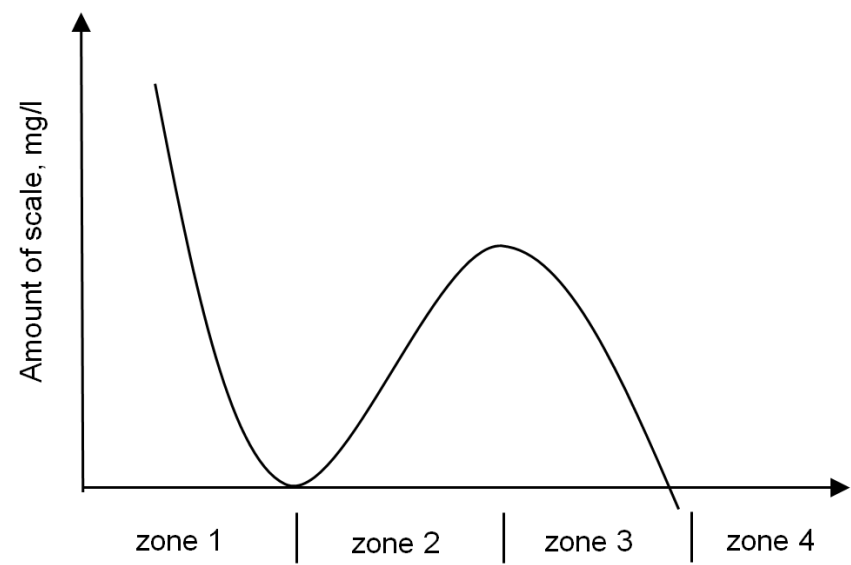

Figure 4: Dependence of the amount of scale on the concentration of the inhibitor

The technology of constant dosing of the salt deposition inhibitor has its limitations. Limitations are imposed by the performance of metering units. Also, at high debits, the time spent by the inhibitor in the receiving area of the pump is short, and its rapid removal occurs, dramatically reducing the efficiency of the technology [26-33].

To prevent scale, a periodic dosing of the inhibitor into the annulus of wells is used. The following are generalized applicability criteria for periodic dosing technology.

Low productivity wells are treated, where there is no immediate removal of the entire volume of the inhibitor by the pump. The condition of incomplete water removal must be met:

$R_{e}<1600$ i $L_{N K T}<L_{c} \cdot \frac{r_{e}}{r_{e}+R_{N K T}}$

where $\mathrm{Re}$ is the Reynolds number for oil;

$\mathrm{L}_{\mathrm{NKT}}$ - pump-setting depth, $\mathrm{m}$;

$\mathrm{L}_{\mathrm{C}}$ - well depth, $\mathrm{m}$;

$r_{e}$ - internal radius of the production casing, $m$;

$\mathrm{R}_{\mathrm{NKT}}$ - internal radius of the production tubing, $\mathrm{m}$.

Gradually, at wells with periodic inhibition, it is necessary to switch to more modern protection technologies - constant dosing of the inhibitor into the annulus and setting the inhibitor in the bottom hole formation zone.

The technology of constant dosing of the scale inhibitor has limitations. Limitations are due to the performance of dosing units. In addition, at high debits, the time spent by the inhibitor in the pump suction area is short, and its rapid removal occurs, which dramatically reduces the efficiency of the technology.

The main advantage of the technology is the guaranteed presence of the inhibitor at the ESP reception and in the well production and the relative cheapness of the method.

Disadvantages include the cost of additional equipment (surface dispenser), its installation and maintenance, as well as the risks of corrosion of the tubing or service column, the lack of protection of the area below the pump suction.

Evaluation of the effectiveness of scale inhibitors for the ability to prevent sedimentation was carried out according to the NACE TM 0374-2007 standard in a liquid solution of the average model of reservoir water of the Priobskoye field.

The test results are shown in Table 4.

Table 4: Evaluation of the effectiveness of scale inhibitors

\begin{tabular}{|l|c|c|}
\hline Scale inhibitor & $\begin{array}{c}\text { Concentration, } \\
\mathbf{m g} / \mathbf{d m}^{\mathbf{3}}\end{array}$ & Effectiveness, $\%$ \\
\hline \multirow{4}{*}{ Fox-03 N } & 5 & 78 \\
\cline { 2 - 3 } & 10 & 83 \\
\cline { 2 - 3 } Infor-1 & 20 & 90 \\
\cline { 2 - 3 } & 5 & 93 \\
\cline { 2 - 3 } & 10 & 98 \\
\cline { 2 - 3 } SONSOL-2001B & 20 & 99,5 \\
\cline { 2 - 3 } & 5 & 84,5 \\
\cline { 2 - 3 } & 10 & 91,4 \\
\cline { 2 - 3 } Insan & 20 & 99 \\
\cline { 2 - 3 } & 5 & 82,6 \\
\cline { 2 - 3 } & 10 & 90,3 \\
\cline { 2 - 3 } & 20 & 99 \\
\hline
\end{tabular}

The results of the experiment showed that the reagent Infor- 1 inhibits the precipitation of salts on the model water most effectively from a starting concentration of $5 \mathrm{mg} /$ $\mathrm{dm}^{3}$.

\section{DISCUSSION}

The sample analysis of the effectiveness of preventing scale on submersible equipment using periodic dosed supply of a scale inhibitor included treatments for 175 wells. The evaluation criteria were changes in the well flow rate and restoration of the dynamic level. Out of 175 treatments, only 29 wells showed no noticeable changes in the flow rate or restoration of the dynamic level.

Thus, processing at 133 wells was technologically successful, i.e. by $82.1 \%$, which is a very good indicator. The main disadvantage of periodic dosing of the salt deposition inhibitor is relatively long periodswhen the well is not protected due to the uneven removal of the inhibitor.

The second disadvantage is the lack of a simple method for constant monitoring of the removal of scale inhibitor.

In particular, the analysis of the removal of the scale inhibitor from wells protected by periodic dosing showed that the inhibitor concentration was below the minimum working concentration for a number of samples.

The results of determining the content of the inhibitor removed from the well showed that almost 30 wells in this 
sample were not protected. The reason for this situation was the rapid removal of the inhibitor along with the annular fluid.

Analysis of water saturation by salt-forming ions showed that the most dangerous zone for salt deposition was the zone of the submersible electric motor and pump. Scale occurs in the bottom-hole formation zone of the reservoir since the water saturation index exceeded 0 , but the potential for salt deposition is significantly less than at the ESP.

It was found that the composition of sediments from the surface of the ESP stages includes calcite and corrosion products, and quartz sand and proppant were found in some scale. The measures taken to protect wells from salt deposition, namely periodic dosing, showed that $82.1 \%$ of the treatment at 133 wells was technologically successful, which demonstrates the obvious disadvantages of periodic dosing (relatively long periods when the well is not protected due to uneven removal of the inhibitor). At wells with periodic inhibition, it is necessary to switch to newer protection technologies - constant dosing of the inhibitor into the annulus and setting the inhibitor in the bottom hole formation zone.

\section{AUTHOR CONTRIBUTIONS:}

Conceptualization, Liliya Saychenko and Dmitry Tananykhin; methodology, Liliya Saychenko; software, Rahman Ashena; validation, Liliya Saychenko, Dmitry Tananykhin and Rahman Ashena; formal analysis, Dmitry Tananykhin; investigation, Liliya Saychenko; resources, Rahman Ashena; data curation, Dmitry Tananykhin; writing — an original draft preparation, Liliya Saychenko; writing - a review and editing, Liliya Saychenko, Dmitry Tananykhin; visualization, Rahman Ashena; Dmitry Tananykhin; project administration, Liliya Saychenko. All authors have read and agreed to the published version of the manuscript.

\section{REFERENCES}

1. Rogatchev, M.K., \& Kondrashev, A.O. (2016). Justification of the technology of in-situ water isolation in low-permeable reservoirs. Journal of Mining Institute, Volume 217, pp. 55-60.

2. Shangaraeva L.A., \& Tananykhin D.S. (2015). The development of energy-saving technologies of oil wells chemical treatment to prevent scale. International journal of applied engineering research 2015, Volume 10, Issue 24, pp. 44157-44161.

3. Kelland M.A. (2015). Field chemistry in the oil and gas industry, 2nd ed.; Profession: Saint-Petersburg, Russia, 607 p.

4. Persiancev M.N. (2017). Oil production in the complicated conditions, Nedra-Businesscenter LLC: Moscow, Russia.
5. Brikov A.V., \& Markin A.N. (2018). Organization of the scale control system on the example of an oil field in western Siberia. Oilfield business, Volume 4, pp. 56-61.

6. Markin A.N., Sukhoverkhov S.V., \& Brikov A.V. (2016). Oilfield chemistry: Analytical methods, Sakhalin regional printing house: Yuzhno-Sakhalinsk, Russia, 212 p.

7. Gareev A.A. (2017). About the mechanism of scale. Oilfield business, Volume 4, pp. 35-45.

8. Khaibullina, K.Sh.; Korobov, G.Y., \& Lekomtsev, A.V. (2020). Development of an asphalt-resin-paraffin deposits inhibitor and substantiation of the technological parameters of its injection into the bottom-hole formation zone. Periódico tchê química, Volume 17 (34), pp. 769-781.

9. Sandyga, M.S., Struchkov, I.A., \& Rogachev, M.K. (2020). Formation damage induced by wax deposition: Laboratory investigations and modeling. Journal of Petroleum Exploration and Production Technology, Volume 10(6), pp. 2541-2558. DOI:10.1007/ s13202-020-00924-2.

10. Shagiakhmetov, A.M., Podoprigora, D.G., \& Terleev, A.V. (2020). The study of the dependence of the rheological properties of gelforming compositions on the crack opening when modeling their flow on a rotational viscometer. Periodico Tche Quimica, Volume 17(34), pp. 933-939.

11. Kashchavtsev V.E. (2002). Role of interstitial waters in the process of precipitation of scale during oil production. Oil, gas and business, Volume 2, pp. 42-45.

12. Zdolnik S.E., \& Akimov O.V. (2009). Manage scaling-a pledge improve the efficiency of oil production. Engineering Practice, Pilot, pp. 66-69.

13. Samoilov A.S., Iolchev A.M. (2018). Analysis of the causes and improving methods for the prevention of scale during the oil well operation on the example of the Arlan field Science. Technic. Technologies (Polytechnic Bulletin), Volume 3, pp. 193-222.

14. Brikova A.V., \& Markina A.N. (2018). Oilfield Chemistry: A practical guide to fighting scale, De'libri: Moscow, Russia, 335 p.

15. Mardashov, D., Islamov, S., and Nefedov, Y. (2020). Specifics of well killing technology during well service operation in complicated conditions. Periodico Tche Quimica, Volume 17(34), pp. 782-792.

16. Morenov, V., \& Leusheva, E. (2017). Development of drilling mud solution for drilling in hard rocks. International Journal of Engineering, Transactions, Volume 30(4), pp. 620-626. DOI: 10.5829/idosi. ije.2017.30.04a.22 
17. Leusheva, E., Morenov, V., \& Tabatabaee M.S. (2020). Effect of Carbonate Additives on Dynamic Filtration Index of Drilling Mud. International Journal of Engineering, Transactions, Volume 33(5), pp. 934-939. DOI: 10.5829/IJE.2020.33.05B.26

18. Koptev, V.Y,. \& Kopteva A.V. (2017). Improving paraffin deposits detection methodology for better ecological safety during hydrocarbon transportation. International Journal of Applied Engineering Research, Volume 12(5), pp. 618-621.

19. Khaibullina, K.S., Sagirova, L.R., and Sandyga, M.S. (2020). Substantiation and selection of an inhibitor for preventing the formation of asphalt-resin-paraffin deposits. Periodico Tche Quimica, Volume 17(34), pp. 541-551.

20. Tomson, N.B. Watson, M.A. \& Fu, G. (2002). Mechanisms of mineral scale inhibition. SPEPF 2002, Volume 18, pp. 192-199.

21. Ragulin V.V. Voloshin A.I., \& Ganiev I.M. (2008). Prospective technology for preventing scale in producing wells. Oil industry 2008, Volume 11, pp. 62-65.

22. Molchanov, A.A., \& Ageev, P.G. (2017). Implementation of new technologies is a reliable way of extracting residual reserves of hydrocarbon deposits. Journal of Mining Institute 2017, Volume 227.

23. Sharafutdinov R.F., Valiullin R.A., \& Gareev A.A. (2018). The problem of scale in electrical submersible pump unit. Oil industry, Volume 9, pp. 116-121.

24. Gareev A.A. (2018). On the issue of predicting scale in installations of electric centrifugal pumps. Equipment and technologies for the oil and gas complex, Volume 5, pp. 37-42.

25. Hisametdinov M.R., Ganeeva Z.M., Zholdasova E.R., Nuriev D.V. Amerkhanov M.I. (2018). Development of a composition for removing deposits of inorganic salts from oilfield equipment in the production of ultra-viscous oil. Oil industry, Volume 7, pp. 39-41.

26. Brikov A.V., Markin A.N., \& Nizamov R.E. (2017). About technologies for supplying scale inhibitors to producing wells. Oilfield business. Volume 9, pp. 5459.
27. Gurbanov G.R., Adygezalova M.B., Pashayeva S.M., \& Abdullayeva N.A. (2019). Effectiveness of preventing scale using an inhibitory composition in laboratory conditions. Oilfield business, Volume 4 (604), pp. 66-69.

28. Kaslivtsev R.V., \& Tokareva N.M. (2016). Analysis of the implementation of the technology of scale inhibitor injection into the reservoir to prevent deposits of inorganic salts in the bottom-hole formation zone of producing wells for the conditions of oil fields in the Republic of Bashkortostan. Oil and gas business, Volume 2, pp. 105-119.

29. Aksenov D.A. (2016). Effectiveness of preventing scale using inhibitors. European Science, Volume 5(15), pp. 5-7.

30. Rahman, P. A. (2017). Analysis of the mean time to data loss of nested disk arrays RAID-01 on basis of a specialized mathematical model. IOP Conference Series: Materials Science and Engineering, 177(1). https://doi.org/10.1088/1757-899X/177/1/012088

31. Skrypchuk, P., Zhukovskyy, V., Shpak, H., Zhukovska, N., \& Krupko, H. (2020). Applied aspects of humus balance modelling in the rivne region of ukraine. Journal of Ecological Engineering, 21(6), 42-52. https://doi:10.12911/22998993/123255

32. Rahman, P. A. (2017). Using a specialized Markov chain in the reliability model of disk arrays RAID-10 with data mirroring and striping. IOP Conference Series: Materials Science and Engineering, 177(1). https://doi.org/10.1088/1757-899X/177/1/012087

33. Zhukovskyy, V., Zhukovska, N., Vlasyuk, A., \& Safonyk, A. (2019). Method of forensic analysis for compromising carrier-lock algorithm on $3 \mathrm{G}$ modem firmware. Paper presented at the 2019 IEEE 2nd Ukraine Conference on Electrical and Computer Engineering, UKRCON 2019 - Proceedings, 11791182. https://doi:10.1109/UKRCON.2019.8879941 